REVISTA ECONOMÍA

Vol. 7I, N. ${ }^{\circ}$ II3 (mayo 20I9), 9I-IO5

\title{
CUESTIONES EPISTÉMICAS EN EL ANÁLISIS DE LA DEPENDENCIA Y DEL CAPITALISMO DEPENDIENTE
}

\author{
JAIME OSORIO \\ UAM-Xochimilco, México
}

Recepción de manuscrito: 26 de abril de 2019

Aceptación de versión final: 30 de abril de 2019

\begin{abstract}
RESUMEN Muchas de las discusiones en las ciencias sociales tienen como trasfondo elementos que están más allá de los problemas aparentemente en disputa. Por ello, es necesario ir más a fondo y develar los fundamentos epistémicos que sostienen tal o cual posición. En lo que sigue, se privilegiará esa perspectiva para intentar esclarecer algunos puntos centrales en la polémica sobre la renovación de la teoría marxista de la dependencia formulada por Claudio Katz y ofrecer respuestas puntuales a su último escrito (2019). Desde esa perspectiva, se podrá dimensionar la consistencia de los argumentos, los límites que el horizonte reflexivo asumido plantea, así como su ubicación en el desarrollo de la teoría de la dependencia.
\end{abstract}

pALABRAS ClaVES Epistemología, negatividad, niveles de abstracción, dependencia.

ABSTRACT Many of the discussions in the social sciences have as a background elements that are beyond the problems apparently in dispute. For this reason it is necessary to go more deeply and to unveil the epistemic foundations that hold this or that position. In what follows will be privileged this perspective to tray to clarify some central points in the controversy about de renewal of the Marxist of Theory of Dependency formulated by Claudio Katz and to offer specific answers to his last writing (2019). From this perspective can be measured the consistency of the arguments, the limits that the reflective horizon assumes, as well as its location in the development of dependency theory.

KEY WORDS Epistemology, negativy, leves of abstraction, dependence.

JEL CODES B14, O19, F54.

UNA REALIDAD SOCIAL OPACA Y UN MUNDO DE FICCIONES REALES

A diferencia de las clases dominantes que le precedieron en la historia, la burguesía es la primera clase que debe ocultar los procesos de explotación y de dominio que lleva a cabo. Ambos procesos destruyen desde los cimientos la promesa civilizatoria con que esta clase se pone la cabeza de la sociedad: construir un mundo de hombres libres e iguales. Por esta razón debe velar aquellos procesos, propiciando la conformación de una realidad social opaca, que es desvirtuada y que se revela ocultándose. Son diversos los procedimientos que operan en tal 
dirección, como la ruptura entre economía y política; la conformación de saberes disciplinarios que fragmentan los procesos de la vida en sociedad y que rechazan la perspectiva de la totalidad; el fortalecimiento de filosofías y epistemologías que asumen lo real como lo inmediatamente perceptible (lo que fortalecerán las corrientes empiristas y positivistas en el conocimiento); el estudio de cosas (pensamiento cosista) por sobre las relaciones sociales; el reduccionismo o la búsqueda de las últimas partes que no tienen partes (átomos), como principio de conocimiento, lo que conduce a asumir al individuo como punto de partida para la explicación en las ciencias sociales; devaluación de las filosofías ontológicas (que se preguntan por la naturaleza del ser); la lógica formal y sus principios de identidad y de no contradicción , rechazando la lógica de la negación (el ser es y su negación de manera simultánea), etc.

Para el capital y sus agentes sociales la particularidad, no pasa solo por lo que la propia realidad oculta, en su inmediatez, sino porque se recrea un mundo puesto de cabeza. De esta forma se conforman ficciones reales. Ficciones porque encubren y desvirtúan la realidad; reales porque dichos trastocamientos alcanzan consistencia social. Como ocurre cuando se ve cotidianamente «salir» el sol, hacer un recorrido por sobre la tierra, para luego ocultarse. Se sabe, no por lo que se ve, sino por conocimientos, que no es el sol el que gira alrededor de la Tierra, sino al revés, que es la Tierra la que gira alrededor del sol. Se crea así una ficción, porque lo que se ve - el sol moviéndose- no es el proceso que realmente acontece. Sin embargo, opera como real, porque es lo que han visto y vemos millones de humanos, y con ello «la visión» gana en consistencia y en verosimilitud.

En la vida en sociedad, establecida la ruptura entre economía y política, se tiene una economía que gira en torno al mercado como cosa, Y allí se presentan individuos que de manera libre y soberana compran y venden mercancías y establecen contratos. Los asalariados llegan al mercado sin que policías los saquen de sus camas ni los obliguen a subirse a transporte público ni a ir a sus centros de trabajo. Todo lo realizan sin ninguna coacción visible. Solo yendo más allá de lo inmediato perceptible, se sabrá que los asalariados se presentan a vender su fuerza de trabajo porque ellos o sus generaciones previas fueron despojados de medios de producción, por lo que no tienen más recurso para poder sobrevivir que alcanzar un salario, vendiendo su fuerza de trabajo. Lo que parecía un proceso puramente económico de libre decisión, está atravesado, sin embargo, por procesos de violencia y coacción política que no se hacen visibles en el mercado. Por ello, dice Carlos Marx, el mercado aparece como el reino de la libertad.

Desde aquí, ya se puede apreciar la ingenuidad empirista que subyace en quienes se conforman con lo que aparece, con lo dado de manera inmediata. Así, algunos afirman que si los salarios son bajos o elevados, ello es resultado de que el valor de la fuerza de trabajo es bajo o elevado (Katz, 2019). Al final, asumen sin más que lo que aparece es lo real y éste se presenta como tal, sin ninguna mediación ni distorsión. En la política, hay individuos que llegados a determinada edad se convierten en ciudadanos. Y, por principio, los ciudadanos son iguales políticamente, porque cada cabeza es un voto y solo un voto. Por tanto, en las decisiones políticas sobre la vida en común, son ciudadanos iguales los que deciden sobre el curso de la vida en común.

Hay que salir de las apariencias o de lo inmediatamente visible para comprender que el voto del ciudadano dueño de un banco y el voto del ciudadano portero del banco, siendo iguales 
en la apariencia, en el fondo no lo son. Porque el poder económico logra que le sean favorables las políticas del Estado y sus leyes, para que aseguren la propiedad y la apropiación diaria del trabajo ajeno de muchos. La política está atravesada por la economía, por más que las dos disciplinas se asuman como autónomas. Por tanto, la igualdad política, solo es una ficción, pero real, porque genera consecuencias con consistencia, como la idea de que todos los ciudadanos participan en igualdad de condiciones (solo un voto) en las elecciones de las autoridades y que, por tanto, es responsabilidad de todos lo que de allí resulte para la vida en común. En el capitalismo no solo se oculta el dominio y la explotación, sino que se reconstruye cotidianamente una nueva realidad. Solo yendo más allá de la inmediatez aparente se puede comprender que el mundo social se nos presenta de cabeza (o al revés) y ponerlo sobre sus pies.

\section{CUÁL LÓGICA: ¿LA DE LA IDENTIDAD O LA DE LA NEGATIVIDAD?}

No existe una única filosofía ni una única lógica en el quehacer de las ciencias sociales y en sus tareas de generar conocimiento. El que prevalezcan unas u otras genera resultados absolutamente diferenciados. En los saberes dominantes prevalece la lógica formal, porque privilegia la idea de una realidad quieta, siempre la misma, sin conflictos. Esa lógica con su principio de identidad, nos dice que si esto es A, solo puede ser A. No hay nada en ese algo que lo lleve a ser otra cosa. Por ello, establece de manera inmediata el principio de no contradicción; si afirmo que esto es A, no puedo afirmar que de manera simultánea es también su negación. La lógica formal con su principio de identidad, deja fija y estática la realidad. No tiene elementos para entender sus movimientos y contradicciones. Y si esa realidad se transforma, es como resultado de procesos externos, de fuerzas exteriores que operan para mover, o bien para transformar.

Las ciencias sociales imperantes no están sustentadas en principios lógicos (ni filosóficos) que permitan entender la lucha de clases, las revoluciones sociales. Éstos y otros procesos históricos y reales les parecen metafísica, o bien procesos que se generan como resultado de fuerzas externas. Pero el marxismo es una teoría que necesariamente debe organizarse y articularse desde otra lógica para poder enfrentar una reflexión que sea capaz de entender los movimientos y convulsiones de la realidad social propiciados en el seno de ella misma, sean la lucha de clases o las revoluciones políticas.

Esa otra lógica asume que el ser es y es simultáneamente también su negación. ${ }^{1}$ Con esta lógica el ser no puede ser pensado, sino en constante tensión y movimiento, entre fuerzas interiores que lo llevan a ser tal y las fuerzas interiores que los impulsan a ser otro de sí mismo. Pero esa tensión y movimiento no es un devenir homogéneo, sino, por el contrario, un proceso heterogéneo, con cambios de cualidad, lleno de saltos, en donde se asumen elementos de lo que perece, para en un proceso de superación, integrarlos a lo nuevo que emerge. Desde esta lógica, es posible apreciar la distancia que presentan señalamientos como los que postulan una ley del valor quieta, estable, petrificada. Solo se puede sostener lo anterior desde una lógica que está muy lejos de la lógica de la negación.

Solo porque existen procesos que llevan a que actúe y opere la ley del valor es posible e inevitable que emerjan tendencias que apuntan a su negatividad o violación. Por sostener lo anterior, el crítico (nos) atribuye la destrucción del «edificio teórico» de Marx y del plusvalor. Así 
señala que «[Osorio] habría postulado que el capitalismo tiende en forma recurrente a sub-remunerar a los asalariados» y que «esa interpretación socava la centralidad de las plusvalía en todo el razonamiento de El capital» (Katz, 2019).

¿Cree nuestro crítico que Marx se hacía el harakiri teórico cuando señala: «[...] [L]a reducción forzada del salario por debajo - del valor de la fuerza de trabajo-, tiene una importancia demasiado grande», para concluir que «gracias a esto, el fondo necesario de consumo del obrero se convierte de hecho, dentro de ciertos límites, en un fondo de acumulación de capital»? (Marx, 1973a, pág. 505) (subrayados de J. O.).²

En el párrafo citado Marx señala que la violación de la ley («que tiene una importancia demasiado grande») permite al capital incrementar la plusvalía. ¿Quién estaría socavando la centralidad de la plusvalía? Ni Marx, ni tampoco quienes destacamos estas afirmaciones de Marx. Simplemente, constatamos que la lógica en la reflexión es otra, diferente al principio de identidad. De allí que el crítico reafirme sus dichos: «Esa lógica (de la identidad, J. O.) se extiende al salario, que expresa el valor de la fuerza de trabajo y no su negación» (Katz, 2019). Pero ya se ha visto que existen salarios por debajo del valor de la fuerza de trabajo, y ello está destacando la negatividad presente en el valor de esa mercancía y en el valor como tal.

Creo que existe más de una confusión. Todo parece indicar que se asume «negación» como «no existente», como si la plusvalía desaparecería si se asume la negación presente en el valor. Y no es esto, sino destacar que «el ser es y no es simultáneamente». Repítase: porque existe una ley del valor es por lo que se puede violentarla. Que se diga que el proletariado es la negación del capital, indica primero que el capital no puede existir sin el proletariado; segundo, que esa relación es contradictoria, esto es, que es un conflicto real, y tercero, señala que ese carácter contradictorio constituye el núcleo de su realidad histórica y de su movimiento. ${ }^{3}$ Nadie asume que porque el proletariado es la negación del capital, el capital no existe. Si no existiera capital, no habría relación interna con el proletariado y, por tanto, no habría negación ni contradicción.

Para mayor escándalo de los que reflexionan atrapados en la lógica de la identidad se tiene que subrayar que los problemas no se remiten solo a salarios por debajo del valor de la fuerza de trabajo; no hay tema y problema relevante en El Capital donde la lógica de la negatividad no se encuentre presente: el valor de cambio como negación del valor de uso; el trabajo abstracto como negación del trabajo concreto; el capital como negación del trabajador; el trabajo muerto como negación del trabajo vivo; la «libertad» del obrero como negación de la esclavitud encubierta al capital; el salario como negación de la explotación; la mercancía como negación de las relaciones sociales entre los productores; el crecimiento de la miseria como negación del crecimiento de la acumulación de capital; la ganancia como negación de la plusvalía; el capital y sus crisis como negación del propio capital. Póngase al final, aunque no es lo último: los trabajadores, el proletariado, como negación del capital, que ya se ha comentado.

Visto desde esta dimensión, parece que los problemas de las lógicas con las que se lleva a cabo la reflexión, nos enfrentan a problemas muchos más amplios que discutir simplemente si Marx consideró o no la negatividad en la ley del valor. La lógica que predomina en una u otra reflexión da origen a realidades no solo diferentes, sino inconmensurables entre sí. 


\section{NIVELES DE ANÁLISIS O NIVELES DE ABSTRACCIÓN}

Una particularidad del marxismo frente a otros cuerpos teóricos, es que presenta en su corpus diversos niveles de análisis o niveles de abstracción. Esto refiere a la presencia de niveles con menores determinaciones, pero que apuntan a destacar y explicar las particularidades que definen los fundamentos de alguna forma de organización de la vida en común, como ocurre con la articulación conceptual para explicar un modo de producción, hasta niveles de mayor concreción y, por tanto, con mayores determinaciones. Así, para el estudio del capitalismo, se tiene análisis a nivel del modo de producción, del sistema mundial, de las formas de capitalismo, de formaciones económico-sociales y de coyuntura.

Las categorías y nociones de los niveles más abstractos van siendo asimiladas redefinidas y recreadas en los niveles menos abstractos o más concretos y, a su vez, en estos últimos niveles se deben crear categorías y conceptos que den cuenta de las particularidades que en esos niveles se presentan, creándose al final un entramado conceptual variado y rico en capacidad explicativa. En los distintos niveles, son diversos los problemas centrales que deben ser resueltos, contando para ello con las categorías apropiadas. A la luz de lo anterior, señalar que Lenin o Rosa Luxemburg «desconocían» la categoría superexplotación no es ningún argumento ni para sugerir que es innecesaria y, menos, para desecharla (Katz, 2019).

Primero, porque los autores anteriores están discutiendo problemas de un nivel de análisis particular, el sistema mundial, que desembocarán en la formulación de teorías sobre la expansión imperialista. Segundo, porque esas teorías - si bien hacen referencias a las colonias y otras «periferias»— no tienen como objetivo explicar éstas y mucho menos el capitalismo dependiente, un asunto teórico de mayor concreción que el que les ocupa. Y tercero, porque existiendo planteamientos en la época en donde se habla de salarios por debajo del valor, como lo señala Marx cuando enumera causas que contrarrestan la caída de la tasa de ganancia (Marx, 1973, t. III), la categoría superexplotación no había sido aún desarrollada teóricamente.

No fue por casualidad que a la luz de lo anterior se señalara que la teoría de la dependencia podía ser considerada como un complemento de la teoría del imperialismo, vista las consecuencias de la expansión imperialista hacia las regiones dependientes (Cardoso, 1972). Incomprensiones en ese mismo sentido son las que están presentes cuando se señala que se ha querido convertir a Marx en un teórico de la superexplotación (Katz, 2019), porque en un escrito (Osorio, 2018a) se ha traído a colación algunas de las múltiples referencias de Marx en El capital a las violaciones del valor diario o del valor total de la fuerza de trabajo. Se ha indicado que Marx en esa obra tiene como una de sus preocupaciones centrales establecer los procesos que permiten la generación de plusvalor en el capitalismo y desde ese piso explicar las bases en las que se desenvuelve la lucha de clases en el modo de producción capitalista. En ese tenor y para esos fines, señala el supuesto de que partirá asumiendo que las mercancías, entre ellas la fuerza de trabajo, se intercambian por todo su valor. Y en esa lógica dedica espacio para explicar los determinantes que operan en el valor de la fuerza de trabajo.

Establecidas las condiciones que hacen posible la generación de plusvalor y la explotación en el modo de producción capitalista, Marx va poniendo de manifiesto procedimientos que lleva a cabo el capital para la vigencia del valor, pero también para violentarlo, ${ }^{4} \mathrm{y}$ pone de manifiesto con ejemplos del funcionamiento concreto del capitalismo inglés, que los procesos en 
su mayor concreción operan en la dialéctica de la negación. ¿O es que alguien cree que el capitalismo inglés, al menos hasta mediados del siglo xix, efectivamente respetaba el valor de la fuerza de trabajo? Marx al menos no. Y allí están todas las múltiples referencias históricas en El capital para confirmarlo. ${ }^{5}$

Pero más allá de señalar tendencias que caminan en esa dirección, Marx no buscaba explicar teóricamente el proceso de superexplotación, ni otorgarle un concepto, a lo sumo lo señala bajo el término de «explotación redoblada» (Marx, 1973b, pág. 511). A nivel del modo de producción en que se mueve, le era suficiente explicar que aun respetando el valor de la fuerza de trabajo, la explotación en el capitalismo es posible.

No deja de ser curioso que a la fecha el crítico no problematice el caudal de páginas y ejemplos en que en el primer tomo de El capital, Marx pone de manifiesto cómo el capital puede violentar el valor diario y el valor total de la fuerza de trabajo. Y aquí no se puede echar la culpa a Friedrich Engels o a algún otro editor del libro por esas páginas, al fin que ese tomo es el único que Marx directamente supervisó sus publicaciones y realizó cambios para ediciones en lenguas diversas. Y curiosamente esas páginas no fueron en lo sustancial alteradas y mucho menos eliminadas. El problema no se resuelve con la fórmula genérica de señalar que la obra de Marx no es un «inconsistente armado de conceptos autodesmentidos», o que «la obra de Marx está asentada en la coherencia y no en la autorefutación». ${ }^{6}$ (Katz, 2019). Pero ¿qué significan o cómo se interpretan aquellas páginas y párrafos en donde, bajo otros términos, Marx está poniendo de manifiesto que el capital superexplota? Silencio.

A lo menos Katz reconoce que esas páginas existen. Por ello, indica que a las varias referencias que se han incluido en aquel escrito «se podría responder con toda la biblioteca de referencias opuestas que domina a El capital» (Katz, 2019). Pero añade: «En última instancia, el propio Marx podría estar equivocado o desactualizado» (sic), para concluir que «lo importante es la coherencia y la consistencia empírica [sic] de un razonamiento» ${ }^{7}$ (Katz, 2019). Por lo dicho anteriormente, Katz pareciera inclinarse por la idea que Marx dejó esas páginas y párrafos por «equivocación o desactualización», ya que a su juicio impera el inmutable intercambio de mercancías por su valor. ${ }^{8}$

\section{EL CAPITAL: NECESARIO, PERO INSUFICIENTE}

No entender el tema de niveles de análisis es lo que lleva a otros autores a señalar que Marx se equivocó en su análisis de las clases, al hablar en El capital solo de tres clases (burguesía, terratenientes, obreros), en tanto que en sus estudios sobre la formación económico-social francesa a mediados del siglo xIx refiere a cinco clases, añadiendo a las tres anteriores el campesinado y la pequeña burguesía, además de fracciones y sectores (Marx, 2005). En el modo de producción, las tres clases mencionadas son las determinantes para entender la dinámica del capitalismo a ese nivel. Pero son insuficientes para analizar la Francia de mediados del siglo xIX, esto es, a una formación económico-social específica y en un tiempo específico.

Señalar, a su vez, que para explicar el capitalismo dependiente no es necesario dar cuenta de nuevas leyes y tendencias o generación de nuevas categorías y que solo hay que remitirse a las que aparecen en El capital, (Katz, 2019), no deja de ser también un error garrafal, porque 
esa postura no asume los distintos niveles de análisis, y la necesidad de señalar leyes, tendencias y categorías específicas para cada nivel, más allá de la concreción de las presentes en los niveles más abstractos.

Si se habla del capitalismo, las categorías y nociones a nivel del modo de producción no pueden ser las mismas que a niveles más concretos. Por tanto, es un despropósito señalar, por ejemplo, que si se quiere hablar de las particularidades del capitalismo dependiente, las tendencias y procesos que lo caracterizan, sintetizado en categorías como ruptura del ciclo del capital o superexplotación, habría que «dirimir si [...] constituyen leyes equivalentes al valor, la acumulación o la pusvalía», además de preguntarse si «detentan el mismo estatuto legal que las reglas generales del sistema capitalista», lo que no ocurre, ya que «carecen de la universalidad requerida para integrar el paquete de leyes del capitalismo» (Katz, 2019) (subrayados de J. O.).

Pero las categorías como ruptura del ciclo del capital o superexplotación, de ninguna manera pueden tener la misma equivalencia ni el estatuto legal que las reglas generales del capitalismo, porque no están hechas para explicar problemas a ese nivel, sino para uno mucho más aterrizado y concreto, que se ubica en las formas de capitalismo, llamado capitalismo dependiente. Ahora, sobre la universalidad de dichas categorías, se tendría que señalar que consideradas todas las categorías, de todos los niveles de análisis señalados, unas son necesariamente más universales, las de los niveles más abstractos, frente a las de los niveles más concretos. Valor y plusvalía son más universales que imperialismo y ésta es más universal, a su vez, que imperialismo alemán, imperialismo estadounidense o imperialismo inglés.

Los universales no son entidades quietas ni fijas, como tampoco los particulares. Que sean uno u otro depende del nivel del análisis. Así, la categoría capitalismo dependiente constituye un universal si se hace referencia al conjunto de particulares que lo conforman, como el capitalismo dependiente brasileño, argentino, boliviano, etc., con lo cual se ha alcanzado un estadio de concreción mayor. Nuevamente, habrá que señalar que para el estudio de los nuevos particulares, las formulaciones de El capital son necesarias, pero insuficientes. No constituyen cualquier capitalismo, sino formaciones económico-sociales capitalistas dependientes. Todo lo que se elabore para la cabal comprensión de ese capitalismo, enriquece la teoría marxista en general y su capacidad de dar cuenta de lo concreto.

Esto no invalida que en el estudio del capitalismo brasileño o boliviano no solo se considere el universal capitalismo dependiente, sino también los de los niveles más abstractos como valor, plusvalía, sistema mundial o imperialismo. Los niveles de análisis no son compartimentos estancos, sino niveles que como vasos comunicantes permiten moverse en una u otra dirección, de acuerdo a las necesidades de la reflexión.

\section{EL PRIVILEGIO DE LAS PARTES, OLVIDANDO EL TODO}

Una condición del análisis que asume la totalidad - como el marxismo- es que no es posible analizar algún elemento o relación de manera aislada, fuera del proceso en donde se constituye y del cual forma parte. Lo anterior tiene sentido cuando se presentan argumentos contrarios a algunas categorías, como en este caso a la superexplotación, desligada de los procesos en los cuales alcanza sentido y, además, un papel fundamental para explicar la reproducción 
del capital en el capitalismo dependiente. En defensa de su posición, Katz afirma que, «en la actualidad, la noción de superexplotación no mantiene ninguna conexión con algún problema significativo de la estrategia anticapitalista» (2019).

¿Y esto se afirma porque en las múltiples movilizaciones y procesos llevados a cabo en las diversas sociedades dependientes latinoamericanas en las últimas décadas no aparecieron ni parecen mantas y carteles que reclamaran ¡Fin a la superexplotación!? Tampoco creo haber visto mantas ni carteles que dijeran ¡Fin a la plusvalía! Entonces, ¿la noción de plusvalía también adolece de conexión con algún problema significativo de la estrategia anticapitalista de nuestros días en la región? La simple formulación del problema en los términos señalados por nuestro crítico pone de manifiesto lo absurdo del planteamiento.

Si algo subyace en los múltiples procesos políticos y movilizaciones sociales ocurridos en las últimas décadas en la región, es el rechazo a la aguda explotación que han sufridos los pueblos, en un periodo de incremento de la voracidad de capitales locales y extranjeros, y redoblada tendencia a la apropiación de tierras, bosques y aguas, amén del repudio al autoritarismo, la corrupción y un sistema político cada vez más alejado de expresar los intereses mayoritarios de la población.

La superexplotación hace referencia a una modalidad particular de explotación que atenta contra el valor diario y el valor total de la fuerza de trabajo, en el contexto de economías dependientes en donde el aguijón productivista que caracteriza al capitalismo industrial desarrollado no alcanza consistencia, porque el capital puede hacer de la apropiación del fondo de consumo y del fondo de vida de los trabajadores, elementos que incrementen la acumulación, lo que es posible porque los grandes capitales sostienen su vocación exportadora, la que privilegia el consumo generado por demandas exteriores, con lo que puede dar las espaldas a las necesidades del grueso de la población local.

En México, para 2018, alrededor del 80 por ciento de la producción y ensamble de automóviles fue volcada al mercado estadounidense, principalmente, y a otros mercados externos. Con ello, la superexplotación se constituye en un proceso que no solo sostiene la reproducción local de capitales, sino que incide en fortalecer la acumulación mundial de capitales, en tanto permite sostener a su vez el intercambio desigual desfavorable a las economías dependientes, así como otras formas de transferencias de valor. Sostener que la superexplotación es el fundamento de la reproducción de capitales en las economías dependientes, es poner de manifiesto que esa reproducción necesariamente presenta diferencias con la reproducción del capital en las economías industriales desarrolladas. De ello intentan dar cuenta nociones como ruptura del ciclo del capital, la propia superexplotación, o desarrollo del subdesarrollo.

Pero economías sustentadas sobre estos cimientos necesariamente presentan particularidades a su vez en el conjunto de la reproducción societal, como modalidades autoritarias de dominio que prevalecen sobre las modalidades democráticas, estados subsoberanos, y agudización de la lucha de clases, todo lo cual convierte a las economías dependientes en eslabones débiles del dominio mundial del capital. No es casualidad, entonces, que sea en regiones dependientes en donde han irrumpido los procesos revolucionarios en el sistema mundial, y no en las economías de mayor desenvolvimiento como inicialmente se planteó por el marxismo; y que América Latina sea un reservorio de la revolución, una región en donde de manera regular 
emergen procesos políticos, bajo muy diversas modalidades, que ponen de manifiesto la actualidad de la revolución (Osorio, 2009).

Los gobiernos populares que se forjaron a inicios del siglo xxi en Venezuela, Bolivia y Ecuador, han sido la última gran expresión de dicha tendencia, más allá de los logros alcanzados y de los límites que presentaron o presentan. Todo esto alcanza mejores explicaciones en la medida que se asume que la violencia del capital en el capitalismo dependiente está instalada de una manera particular en la propia dinámica de la reproducción, lo que hace posible que predominen los signos de barbarie por sobre los civilizatorios. La agudización de la lucha de clases en la región no es resultado, entonces, de factores culturales o genéticos, sino que está marcada por la dinámica de la particular forma de capitalismo y de explotación que impera en el marco de la inserción de este capitalismo en el mercado mundial, y de la historia de lucha de clases que el capital propicia.

Desde esta perspectiva, y vista la superexplotación en la totalidad de la dinámica del capitalismo dependiente y de su papel en la acumulación y en la lucha de clases local y a nivel mundial, constituye una desmesura señalar que «la defensa del concepto [de superexplotación, J. O.]» se lleva a cabo «sin ninguna preocupación por su relevancia política práctica», y añadir que «esa actitud (la de los otros, claro está) retrata una afinidad puramente académica hacia esa noción» (Katz, 2019)

¿Y qué afinidad retrata la forma de reflexión que el crítico postula en general y sus desvaríos sobre la supexplotación? Política pura. Solo cabe preguntarse la adecuada para quiénes. Quizá nuestro crítico dé por sentado que como se ha pronunciado en contra de que Donald Trump meta las narices en Venezuela y otros posicionamientos políticos que sería absurdo desconocer, ello supondría que ha quedado inmune a toda crítica. Pero esta es ineludible en el debate teórico-político propiciado. Y aquí no tiene sentido hacerse la víctima - se «pretende excluir nuestro enfoque de ese privilegiado círculo» del dependentismo-, como sería postular que alguien expulsó a Cardoso y que no fue su propio quehacer teórico y político el que lo excluyó del «dependentismo».

Ni tampoco tiene sentido jugar a la ingenuidad, convocando al pluralismo - «reconocer la existencia de distintas corrientes al interior de una misma escuela de pensamiento, “¿el dependentismo?"»-, como si fuese posible conciliar en el seno de la teoría marxista de la dependencia posiciones que sostienen el peso de la superxplotación para explicar el capitalismo dependiente, por razones como las arriba señaladas, con otra que llama a abandonarla y quedarnos con la sencilla solución de salarios bajos porque el valor de la fuerza de trabajo es bajo.

\section{LA PERSISTENTE CONFUSIÓN ENTRE SUPEREXPLOTACIÓN Y PAUPERISMO ABSOLUTO}

Nuestro crítico señala que él no asume la confusión de Cueva de asimilar superexplotación a pauperización absoluta. En un escrito anterior (2018a) se señalaba que pagos por debajo del valor de la fuerza de trabajo no implican necesariamente pauperización absoluta, porque la canasta de consumo de los asalariados se incrementa al paso del tiempo como resultado de la transformación de nuevos valores de uso en bienes salarios, como resultado de su abaratamiento y por la propia sociabilidad reinante. 
De esta forma la masa de valores de uso que consume un trabajador en el siglo xxi y que definen el valor de su fuerza de trabajo, es muy superior a la masa de valores de uso de un trabajador en el siglo xx, al incluir refrigeradores, televisores, celulares, etc. Estos últimos bienes ganan enorme peso en el consumo en tanto resuelven nuevas necesidades sociales impostergables, como poder hacer compras de leche o víveres una vez a la semana y mantenerlos refrigerados, cuando ya la mujer también se ha incorporado al mercado de trabajo, por ejemplo. El problema es que en una economía en donde reina la superexplotación, la adquisición de estos bienes se hace a costa de otros bienes indispensables, como podría ser gastos en medicinas en consultas médicas, dentistas, para no hablar de disminuir el consumo de carne, huevo, frutas y verduras o vestimenta. Para el crítico, este tipo de procesos son «simples retrato de la explotación» y de la «irracionalidad del consumo» que incentiva el capitalismo. Katz razona acá como el liberal que considera que los trabajadores en el siglo Xxi no deben consumir refrigeradores, televisores o celulares, bienes «superfluos», y que deben limitarse a adquirir «los bienes esenciales».

Con este planteamiento, que denota qué poco entiende de lo que determina el valor de la fuerza de trabajo, pareciera indicar que en las protestas de los trabajadores argentinos frente a los agudos encarecimientos de servicios y bienes básicos que lleva a cabo en los últimos años el gobierno de Mauricio Macri, que los tiende a marginar no solo de consumos «superfluos», como los señalados por Katz, sino también de «bienes esenciales», lo que se tiene es un ajuste en donde los salarios bajan quizá porque debe haber bajado el valor de la fuerza de trabajo. ¿Quién «socava la centralidad de la plusvalía»? Porque hay que diferenciar las formas cómo ésta se genera de manera predominante. No es lo mismo que sea por plusvalía relativa o por apropiaciones al fondo de consumo o al fondo de vida.

Nuestro crítico pide que se identifique en qué escrito señala la asimilación de superexplotación y pauperización absoluta que se ha indicado. No hay que ir a otros escritos. En el propio texto que se ha comentado, señala: «Justamente porque a nuestro entender la vigencia de la superexplotación en el grueso de la población laboral — del centro o la periferia-implicaría su empobrecimiento absoluto, restringimos su alcance a una minoría de los desposeídos» (sic). A ello agrega que «Osorio [...] acepta la vigencia de ingresos por debajo del valor de la fuerza de trabajo para el grueso de los asalariados de la periferia. [Pero Osorio] no registra que esa situación amenazaría la subsistencia de los asalariados» (sic). Y señala para menor duda: «La superexplotación como norma en la periferia solo regiría en las circunstancias de pauperización total» (Katz, 2019) (todos los subrayados de J. O.).

\section{¡TRES MODALIDADES DE SUPEREXPLOTACIÓN!}

En un vivo retrato de la confusión en que se posiciona, el crítico indica que intento «amalgamar tres diagnósticos incompatibles» sobre la superexplotación: uno, «que la superexplotación continúa operando como la gran divisoria de las economías desarrolladas y periféricas»; dos, «que con la globalización» la superexplotación «se ha extendido a las metrópolis», y tres, que la superexplotación «se remonta a la época de Marx». Y concluye: «Los tres señalamientos son obviamente contradictorios. Si la superexplotación persiste como especificidad de la 
periferia, no puede generalizarse al centro». Además, «si en las últimas décadas [la superexplotación] se introdujo en los países desarrollados, no se remonta a los años de Marx». Por último, «si [la superexplotación] ya estaba presente en el siglo xIX, carece de especificidad contemporánea» (Katz, 2019).

El hecho de que el capitalismo desarrollado repose desde el siglo XIX de manera creciente en la plusvalía relativa, ¿ello significa que dejó de tener presencia la plusvalía absoluta en ese capitalismo? No es difícil señalar que no. Solo que ahora se articula con el conjunto del proceso de reproducción de otra manera, sin tener la relevancia que alcanzó en los inicios del capitalismo, pero sigue siendo necesaria en esa reproducción, en términos históricos, por lo que mantiene a su vez relevancia teórica. ${ }^{9}$

Ya lo he señalado antes: Marx sí remite a procesos que con el lenguaje actual se lo caracteriza como superexplotación. ¿Quién sostiene que ésta no operaba en los orígenes del capitalismo? Ya se ha comentado que Marx refiere extensamente a esa modalidad de explotación en El capital. La particularidad que la superxplotación presenta en nuestro tiempo en el capitalismo desarrollado reside en que hoy no juega el papel que cumplía anteriormente en ese capitalismo, y no se la nombraba como hoy se lo hace. Y ésta es una «especificidad» histórica y «contemporánea». Por el papel que cumple, se entiende el peso en la reproducción del capital, su incidencia en la conformación de mercado interno, en incentivar o desalentar el desarrollo tecnológico, en las posibilidades de acuerdos entre clases, en las posibilidades de formas más democráticas o más autoritarias de gobiernos, etc.

Y es en dinámicas diferenciadas como las anteriores, lo que propicia que la superexplotación tenga un peso fundamental en el capitalismo dependiente y no lo tenga, aunque se haga presente, en el capitalismo desarrollado, antes o ahora. En el primero la superxplotación [que no pauperismo absoluto] afecta al grueso de la población asalariada y es estructural a la reproducción capitalista, es decir, no aparece en algún tiempo y luego desaparece, porque además también está condicionada por los procesos estructurales de intercambio desigual. En tanto en el capitalismo desarrollado emerge particularmente en momentos de crisis y solo por más largo tiempo en franjas muy reducidas de la población obrera, como migrantes, o en sectores subempleados crónicos.

\section{EL ERROR DE ESTABLECER DICOTOMÍAS: ¿SUPERXPLOTACIÓN O TRANSFERENCIAS DE VALOR?}

Frente a la insistencia de plantear la dicotomía superxplotación o transferencias de valor, repítase lo ya señalado: «Sin intercambio desigual, no hay dependencia; sin superexplotación, no hay capitalismo dependiente; sin capitalismo dependiente, no hay intercambio desigual. Y así se genera una espiral en donde las causas se convierten en consecuencias y las consecuencias se convierten en causas» (Osorio, 2018b).

En su afán de deshacerse de la superexplotación, de su significación en el capitalismo dependiente y de convertir las transferencias de valor en la explicación del subdesarrollo y todo lo referido a las determinaciones de la dependencia, al fin que «la dinámica de las transferencias aporta las respuestas que la tesis de la superexplotación no logra encontrar», Katz intenta 
relativizar el énfasis unilateral en que cae señalando que «todos los marxistas postulamos que los fondos drenados al exterior se basan en una apropiación del esfuerzo laboral de los trabajadores», «se nutren del sudor de millones de oprimidos» (Katz, 2019). Faltaba menos. Y con esto, para el crítico los problemas han quedado en orden.

Pero no basta decir que en las transferencias de valor..., hay transferencias de valor. (¡Vaya descubrimiento!). Falta responder cómo se generó ese valor. ¿Las formas de explotación no tienen sentido? ¿Da lo mismo plusvalía absoluta que relativa? ¿Es igual salarios que respetan el valor de la fuerza de trabajo de salarios que violentan ese valor? ¿Importa solo de dónde salen esos fondos y a dónde van a parar, sin preguntarnos qué consecuencias propician al interior de donde salen, más allá de la vaguedad que generan subdesarrollo? ¿Y cómo generan subdesarrollo? ¿Qué mecanismos, en esas condiciones, hacen factible la acumulación y la reproducción de capitales?

Lo que para nuestro crítico es haber llegado al final del camino es solo el comienzo de una ruta llena de problemas, en donde tarde o temprano se topará con las determinaciones del capitalismo dependiente. Nadie que quiera explicar el «subdesarrollo» y el capitalismo dependiente puede ahorrarse la tarea de formular conceptos y categorías que permitan dar cuenta de los procesos económicos, políticos y sociales que hacen posible que el «subdesarrollo» y el capitalismo dependiente se reproduzcan. $\mathrm{Y}$ en ese tenor es que tienen relevancia los valores de uso cómo la región se insertó y se inserta al mercado mundial; el que predominen en nuestra historia patrones de reproducción exportadores, que propician rupturas del ciclo del capital, que alientan la superexplotación, que no alientan el aguijón productivista y el desarrollo de ciencia y tecnología; que reclama Estados subsoberanos, con clases dominantes locales subordinadas a proyectos imperialistas, sin proyectos nacionales, que el subdesarrollo sea lo que se desarrolla, etc.

Se puede estar en desacuerdo con las nociones y categorías que actualmente se emplean. Lo que parece absurdo es lanzar esas nociones (el agua sucia) junto con la bañera (capitalismo dependiente). Y levantar banderas para indicar que ahora, con las trasnferencias de valor, se tiene la panacea explicativa. Y claro, y con la renta, por supuesto. Lo más serio es que no se vea la desnudez teórica en que se instala una tal propuesta. No es por acaso que Marx señale: «La verdadera economía política comienza allí donde el estudio teórico se desplaza del proceso de circulación al proceso de producción» (Marx, 1973, tomo III, pág. 325).

Parece que no se puede esquivar el análisis de cómo opera la explotación. Y en el capitalismo dependiente opera superexplotando. Por ello es factible señalar que el intercambio desigual y otras formas de transferencias de valor de América Latina al mundo desarrollado, a lo menos desde mediados del siglo XIX en adelante, no son sino otra cara de los procesos de superexplotación, modalidad de explotación que violenta el valor de la fuerza de trabajo, y que hace posible que parte del fondo de consumo y del fondo de vida de los trabajadores se conviertan en fondo de acumulación, sea para hacer factible el intercambio desigual y otras transferencias de valor, sea para compensar sus vigencias.

Las dicotomías son propias del pensamiento que se plantea optar entre esto y aquello, cada uno fijo, quieto, inmutable: el autoritarismo o la democracia; la libertad o la esclavitud; sujeto u objeto, sociedad o naturaleza, excluidos o incluidos; valor de uso o valor. Se puede señalar 
que la exclusión (del empleo y del consumo, por ejemplo) en el capitalismo no es sino una forma de inclusión en la lógica del capital (Osorio, 2012). Plantear como dicotomías procesos que están relacionados, es caminar directo a establecer una exterioridad, que cierra el paso a lo que los propicia y relaciona, que es siempre un proceso al interior.

\section{TEORÍA DE LA DEPENDENCIA Y TEORÍA DEL CAPITALISMO DEPENDIENTE}

La historia que hizo posible que los problemas abiertos con la noción de dependencia cristalizaran en una teoría fue relativamente breve, ${ }^{10}$ pero en un tiempo social tremendamente condensado, cargado de disputas políticas y teóricas, por la agudización de la lucha de clases, acelerados por triunfos como la revolución cubana en 1959, y aletargados por derrotas como el golpe militar de A. Pinochet en Chile en 1973 y demás golpes en el Sur del continente.

En ese condensado proceso hubo una primera etapa en donde declararse «dependentista» fue un asunto relativamente factible y para muchos una moda intelectual, como tantas, al fin que la dependencia era asumido como un problema generado por elementos externos, como el deterioro en los términos de intercambio, ajenos a la responsabilidad de las clases dominantes locales. En este periodo, muchos autores de la CEPAL o del ILPES escribieron sobre la dependencia. Fue en las oficinas de esta última institución en donde F. H. Cardoso y E. Faletto escribieron su libro Dependencia y desarrollo en América Latina (1969).

Pero este escenario comienza a modificarse cuando R. M. Marini publica o da a conocer en congresos los primeros escritos, en 1972, que darían forma a su libro Dialéctica de la dependencia (1973). Su quiebre con las esperanzas del desarrollo removiendo «obstáculos» que impedirían avanzar, como las rémoras semifeudales en el agro, o la desmistificación de la industrialización y su papel que confirmaba las tesis de A. G. Frank según la cual la región solo puede esperar el desarrollo del subdesarrollo de proseguir bajo relaciones capitalistas, así como llenar de significación teórica y política a las formulaciones sobre la superexplotación y el intercambio desigual, hicieron que el escenario comenzara a decantarse. Y reconocerse como dependentista ya no será lo mismo. La impronta anticapitalista del problema no era un asunto menor.

Es en este contexto en donde las tareas prioritarias pasarán por develar las tendencias y procesos que definen el capitalismo dependiente, que comenzará a hablarse cada vez más de una teoría marxista de la dependencia, ${ }^{11}$ y ya no simplemente de teoría de la dependencia, lo que propicia que posiciones antes convergentes comiencen a mostrar sus claras diferencias. No fue una casualidad, entonces, que las críticas anteriormente dirigidas a Frank pasaran a concentrarse en Marini y, particularmente, en las nociones de superexplotación, de intercambio desigual y también en la propia idea de un capitalismo dependiente.

Es en este cuadro que Cardoso inicia su toma de distancias con Marini desde 1972, con su artículo Notas sobe el estado actual de los estudios de la dependencia, y, más tarde, la profundice en 1978 publicando, junto a José Serra, Las desventuras de la dialéctica de la dependencia. Cabe destacar que Marini no se encontró solo en la defensa de las tesis del capitalismo dependiente. Vania Bambirra salió al paso de las principales críticas publicando su libro Teoría de la dependencia: una anticrítica (1978), siendo Agustín Cueva, Octavio Rodríguez y Enrique Semo, en ese orden en el índice, los destinatarios de las críticas principales. 
En esta línea de razonamiento, el trabajo de Claudio Katz se ubica en el amplio campo de lo que se conoce como teoría de la dependencia, que se plantea el tema de la dependencia de manera prioritaria, en una posición que rechaza el planteamiento de particularidades y tendencias de algo referido al capitalismo dependiente, siguiendo la línea en donde destacan Cardoso, desde fuera del marxismo, y Cueva, desde el marxismo ortodoxo de los partidos comunistas.

La publicación de un sinnúmero de antologías sobre la dependencia ha ayudado a alimentar la confusión señalada, como resultado de no establecer las diferencias teóricas y políticas entre autores, en donde Cardoso, Sunkel, Frank y Marini quedan todos en el mismo paquete. En rigor, no todos los autores que hablan o hablaron de dependencia se incluyen en la teoría marxista de la dependencia, para los cuales la explicación del capitalismo dependiente, desde los procesos y formas como este capitalismo se inserta al mercado mundial, se constituye en el centro de su reflexión.

\section{NOTAS}

1 Hegel G. W. F., Ciencia de la lógica (2011). Para versiones más accesibles, consúltese de Pérez Soto C. (2008) y Grespan J. (2012).

2 No postulo que la superexplotación es el fundamento de todo capitalismo, como pudiera desprenderse de lo señalado, sino solo del capitalismo dependiente. El hecho de asumir la extensión de la superexplotación al capitalismo desarrollado de manera acotada, sea a franjas de la población y/o en tiempos particulares, no se lleva a cabo ni genera las mismas consecuencias que en el capitalismo dependiente, como se verá más adelante.

3 Este último ejemplo lo tomo de un correo que el profesor Carlos Pérez Soto me envío, a consulta expresa sobre el tema. Pérez Soto (2008), en particular, la categoría Nada.

4 Esta dinámica es la que destaca Marini cuando indica: «El desarrollo de las relaciones mercantiles sienta las bases para que una mejor aplicación de la ley del valor tenga lugar, pero simultáneamente crea todas las condiciones para que jueguen los distintos resortes mediante los cuales el capital trata de burlarla» (1973, págs. 32-33), (subrayados de J. O.).

5 Muchas de esas referencias son las que se recogen en Osorio (2018a).

6 Desde la lógica de la identidad, quieta e inmutable, tiene sentido que cuando se manifiesta la negación, se señalen términos como "conceptos autodesmentidos» o «autorefutación». Porque existe ley del valor es que se la puede violentar.

7 Ni Marx hace referencias empíricas para establecer el valor de la fuerza de trabajo, y Katz, en los escritos que se comentan, asume sin más que salarios bajos es igual a valores bajos de la fuerza de trabajo. Por tanto, nuestro crítico confunde «consistencia empírica» por "consistencia lógica».

8 No importa que la prensa señale un sinnúmero de ejemplos semanales, sino diarios, donde se violenta el valor. Véase una píldora, en donde los actores no son pequeños capitales actuando en México, Honduras o Filipinas. En Estados Unidos, el regulador del mercado de valores (SEC, por su siglas en inglés) acusa a Volkswagen que «instaló un dispositivo electrónico en los coches para burlar los controles» de contaminación. «La SEC [...] considera que la compañía realizó "una serie de comunicaciones engañosas"», lo que le permitió «acudir al mercado de bonos y recaudar 13 mil millones de dólares entre abril de 2014 y mayo de 2015», y que «los ejecutivos de la compañía conocían que más de medio millón de vehículos en Estados Unidos excedían los límites legales» de gases contaminantes. El País, 16 de marzo de 2019, pág. 38.

9 En su respuesta a Cardoso F. H (1978), Marini señala lo anterior, ante la afirmación de aquel que la plusvalía absoluta podía seguir teniendo relevancia histórica, pero ya no relevancia teórica, ya que el capitalismo - así, en general - en la actualidad se rige por la plusvalía relativa, con lo cual solo habría de ocuparse de esta forma de plusvalía. (Marini, 1973). 
10 En el artículo Osorio J., El marxismo latinoamericano y la dependencia (1985), se realizó un primer balance de este proceso.

11 «La tarea fundamental de la teoría marxista de la dependencia consiste en determinar la legalidad específica por la que se rige la economía dependiente» (Marini, 1973, pág. 99).

\section{REFERENCIAS}

Bambirra, V. (1978). Teoría de la dependencia: una anticrítica. México DF. México: Serie Popular Era.

Cardoso, F. H. (1972). Notas sobre el estado actual de los estudios de la dependencia. Revista Latinoamericana de Ciencias Sociales, (4), (s. d.).

Cardoso, F. H. y Serra, J. (1978). Las desventuras de la dialéctica de la dependencia. Revista Mexicana de Sociología, (número extraordinario), (s. d.).

Cueva, A. (2007). Entre la ira y la esperanza. Buenos Aires, Argentina: Antología ClACso-Prometeo Libros,

Grespan, J. (2012). O negativo do capital. Sao Paulo, Brasil: Expressao Popular.

Hegel, G. W. F. (2011). Ciencia de la lógica (vol. I). Madrid, España: Abada Editores /Universidad Autónoma de Madrid.

Katz, C. (2019, marzo). Actualización o veneración de la teoría de la dependencia. Recuperado de http:// lahaine.org/katz/

Marini, R. M. (1973). Dialéctica de la dependencia. México DF, México: Serie Popular Era.

Marini, R. M. (1978). Las razones del neodesarrollismo (o por qué me ufano de mi burguesía). Revista Mexicana de Sociología, (número extraordinario), (s. d.).

Marx, C. (1973a). El capital (tomo I). México DF, México: Fondo de Cultura Económica.

Marx, C. (1973b) El capital (tomo III). México DF, México: Fondo de Cultura Económica.

Osorio, J. (2012). Estado, biopoder, exclusión. Análisis desde la lógica del capital. , Barcelona, España: Anthropos-UAM.

Osorio, J. (2018a). Acerca de la superexplotación y el capitalismo dependiente. Cuadernos de Economía Crítica, (8), (s. d.).

Osorio, J. (2018b). Los avatares de una nueva interpretación sobre el subdesarrollo y la dependencia. Herramienta web n. 24. Buenos Aires, Argentina.

Osorio, J. (1984). El marxismo latinoamericano y la dependencia. Cuadernos Políticos, (39), (s. d.).

Pérez Soto, C. (2008). Desde Hegel. Para una crítica radical de las ciencias sociales. México DF, México: Editorial Itaca. 
